\title{
SOCIAL MEDIA AND PARA SOCIAL INTERACTION AMONG LEBANESE YOUNG ADULTS
}

\section{Melissa Samir Araigy}

Phone: +96171298881

E-mail: Melissa_araiji@hotmail.com

Lebanon

\section{ABSTRACT}

This research is designed to see the level of parasocial interaction among Lebanese young adults aged 18-35 years old. The data of 50 respondents were analyzed using the descriptive technique. The results showed that the level of parasocial interaction among Lebanese young adults is neutral. Results also showed that Instagram is the most used social networking sites to follow celebrities. In addition, the time spent on social media among Lebanese young adults is 3-5 hours per day, which might increase the level of parasocial interaction in the future.

\section{Keywords: Social media, television, parasocial interaction, parasocial relationship, celebrity}

\section{INTRODUCTION}

\subsection{Background of the Research}

Parasocial interaction is a theory originated with the article "Mass Communication and Parasocial interaction" in 1956 by Donald Horton and Richard Wohl to refer to a kind of psychological relationship experienced by an audience member in their mediated encountered with a certain celebrity in media, especially TV (Horton \& Wohl, 1956).

A celebrity is a person who can generate large-scale public and mass media attention. He/she can invoke fantasy, affiliation, gossip, identification and attachment in people (Rindova, Pollock, \& Hayward, 2006).

According to Spitzberg and Cupach, people play an important role in the creation of a celebrity. The individual move from a normal person to a celebrity when a strong fan base lifts this person into fame. The degree of fans ranges from being a conservative to a worshipper (Spitzberg \& Cupach, 2007).

Traditional media especially Television was known to give the illusion of face to face relationships with the viewer and the celebrity (Horton \& Wohl, 1956). This relationship includes little or no sense of effort, responsibility or obligation on the part of the celebrity. It is practically one-sided, mediated, controlled by the viewer and not susceptible to mutual development (Horton \& Wohl, 1956).

The researchers focused their study on the talk shows where the celebrity conducts informal conversations with the people who feel like they are part of the conversation. This format encourages the viewer to interact with the celebrity on the program, even if they were unable to be a part of the conversation. Thus, this parasocial interaction leads to a parasocial relationship. The parasocial relationship is the continuous feeling of knowing the celebrity long after the program had ended (Stever, 2017).

Regular TV viewers come to feel that television personalities are familiar to them and considered almost as their friends. They observe, interpret his/her appearance, his/her voice and his/her gestures and his/her tone of voice (Allaby, n.d). If they encounter those personalities in the street, they might involuntarily smile in recognition that they know them, when in fact they don't.

The audience offers a continuing relationship where the appearance of the celebrity is planned, counted on and integrated into the routine of his daily life. He knows almost every single detail about the celebrity public life as well as his private life. Thus, the "fan" starts to believe that he knows the celebrity, understand his character and appreciate his values more profoundly than others do. The celebrity is then considered as a friend, role model, counselor and comforter (Horton \& Wohl, 1956).

With the rise of social media, celebrity figures have become more accessible than ever. Social networking sites such as Instagram, Facebook, and Twitter, connected people with their favorite celebrity. 
The majority of the media's content is focused on celebrities, their personal and professional life. We can notice this not only in television, magazines, news, movies but also on social media. Social media reinforced parasocial interaction in a unique way (Phelbs, 2011).

Since social media is connecting people with celebrities, media consumers might feel intimately connected to those figures by supporting them and even believing that they know them personally. This relationship can be called imaginary since the celebrity has never met the consumer which is often called a parasocial relationship. The rise of social networks may strengthen parasocial relationships and made parasocial interactions more common in our society (Phelbs, 2011).

Reality TV shows allow viewers to know the most personal and intimate lives of celebrities, and celebrities openly share their activities and opinions through various social media outlets such as Facebook, Twitter, and Instagram (Bennett, Rossmeisl, Turner, Holcombe, Young, Brown, \& Key, 2017).

Since social media allows for 24-hour access to media users, parasocial interaction has developed to a more interactive environment. Internet dependency may lead to increased parasocial interactions. Currently, people can communicate easily with their personae which may increase the strength and intimacy of parasocial interactions. Thus, the feelings of loyalty, gratitude, affection, encouragement, and longing toward the celebrity may increase (Bennett, Rossmeisl, Turner, Holcombe, Young, Brown \& Key, 2017).

Social media sites, such as Facebook, Instagram, and Twitter, increase the chance of viewers expressing their feelings. This might increase the sense of knowing the persona and the perception of parasocial interaction. However, if the viewer doesn't share the majority of the celebrity viewpoint, he is not considered as a loyal follower, and he is not likely to participate in the parasocial relationship.

Researchers proposed that parasocial relationships are important to viewers, because of the support that the viewer might gain from the relationship. For example: people who watched the American TV show, Ellen or Oprah, that share the past experiences and history of the celebrity with the audience, considered that parasocial relationships helped them to get through tough times (Bennett, N., Rossmeisl, A., Turner, K., Holcombe, B., Young, R., Brown, T., \& Key, K, 2017). Parasocial interactions give people favorable self-concepts such as social mobility and status. These self-concepts might be aspired towards through his/her parasocial interaction with a celebrity (Horton \& Wohl, 1956).

According to Horton \& Wohl, the prestige of the celebrity is perceived to transfer onto the consumer. Therefore, the person basks in the reflected glory of the celebrity. This reflected glory is a phenomenon studied by researchers in the 1970s and had been developed later with impression management theory (Cialdini, Borden, Thorne, Walker, Freeman \& Sloan, 1976).

Previous studies showed that people sometimes wear the same clothing as celebrities, or add them as friends on their social media sites to bask in the reflected glory of the celebrity (End, 2001).

Parasocial interaction is then used by a person as a mean for seeking attention from high-status individuals within their networks (Horton \& Wohl, 1956).

Another reason that people embark on parasocial interaction is recapitulation. It is described as a feeling of nostalgia that offers people a chance to relive former events (Horton \& Wohl, 1956).

Consumers might be involved in parasocial interaction to satisfy their nostalgia. They might even live through the celebrity since they realize that the celebrity's lifestyle is unachievable (Horton \& Wohl, 1956).

The level of parasocial interaction depends upon the amount of media exposure. It also occurs with the increasing levels of psychological distance, abstraction and face to face encounter with strangers (Giles, 2002). Thus, parasocial interaction exists in a range from low to high involvement. As parasocial interaction become more abstract, the potential for face to face relationship decreases (McCutcheon, Lange \& Houran, 2010).

When people interact with celebrities through TV shows or social media, they may exhibit imitative behavior. Once the consumer crosses from the viewing episode to these behaviors, a parasocial relationship starts to be initiated (Giles, 2002). 


\subsection{Statement of the Problem}

Social media is rapidly changing our world, where the distinction between mediated and non-mediated worlds becomes blurry and the effects and roles of fans and celebrities are switched and expanded. It seems important that we understand the interaction that occurs between people and celebrities on such mediums. the purpose of this study is to see the level of parasocial interaction in our society with the rise of social media.

\subsection{Significance of the Study}

This study will add to the current literature on mass media and expand the literature on parasocial interaction. the research will help in revealing all the important materials and analyzing them to get a significant approach to the level of parasocial interaction and its relation to social media. for the findings, my thesis will serve scholars and researchers for further studies in the field of mass communication in Lebanon.

\subsection{Research Question}

RQ: What is the level of parasocial interaction among Lebanese young adults who consume social media?

\section{CHAPTER 2}

\section{LITERATURE REVIEW}

Researchers who have previously studied parasocial interaction have related it to many fields including psychology, sociology and media studies. They have researched also how parasocial interaction may influence a person behavior and how it affects celebrity fans (Laken, 2009).

\section{1- Social penetration theory}

Social penetration theory was developed in 1973 by Altman and Taylor, who suggested that the exchange of information functions in the development of interpersonal relationships. It is also described as a process of bonding that moves a relationship from superficial to more intimate (Altman \& Taylor,1973). Social penetration is directly related to self-disclosure, the process of revealing information about oneself (Carpenter \& Greene, 2016). It increases intimacy in relationships to a certain point. Social penetration can occur in many situations including friendships, romantic relationships, work relationships and social groups. The theory is also applied in computer mediated communication networks such as online social networks (Carpenter \& Greene, 2016).

Social penetration theory describes the public image and the private image. The public image is the outer layer of a person that is visible to others while the private image is only revealed over time through disclosure. The theory includes several layers including middle layers, inner layers, core personality and superficial layers. Middle layers include social attitudes of the person. Inner layers include goals, secrets, fantasies, hope, fears and spiritual values. Core personality includes the most private information about the person. Superficial layers include shallow information such as likes and dislikes in style, clothing, and music (Carpenter \& Greene, 2016).

The exchange of information is the basic of a relationship. Thus, the number of topics discussed and depth, the range of information and the degree of intimacy that guides these interactions are the major factors of the social penetration theory. The various topics discussed range from hobbies, family, professional and educational background, food and clothing style (Carpenter \& Greene, 2016). Depth include the degree of intimacy that lead topic discussions, such as, discussing life goals, feelings associated with family, lover, husband or boyfriend problems.

Social penetration theory includes orientation, exploratory affective exchange, affective exchange and stable exchange (Taylor \& Altman, 1987). Orientation occurs when people share only superficial information about themselves. In this stage, people are careful when disclosing information and tend to rely on the image that is portrayed to most people. They reveal little information about themselves to the public and act in socially desirable way.

The exploratory affective exchange suggests that people share more details beyond the superficial information. There may be an increase in the range of the topics discussed, but these topics still reveal the public self (Taylor $\&$ Altman, 1987). The personality begins to emerge in this stage. 
The affective exchange suggests that more intermediate information is shared and interactions are increasingly casual. Here, people reveal some intimate information about their private life. This stage includes comfort and further commitment (Carpenter \& Greene, 2016).

The stable exchange suggests that the most intimate information about the private life is continuously revealed. It is characterized by breadth, depth and openness of topics as well as honest, intimate, spontaneous in expression of behaviors, feelings and thoughts (Carpenter \& Greene, 2016).

Social media is providing people with means of self-disclosure. Celebrities are sharing intimate details about their life including what they eat, what they wear, their favorite movie, their favorite places, their feelings towards their children and spouses, their daily problems. All this information is shared with their fans and followers on their public profile which might help in developing parasocial relationship.

\section{2- Social exchange theory}

Social exchange theory was developed to explain communication and interaction. It is based on an economic framework in which rewards, resources and costs, are transferred. The theory is the result of an exchange process. The purpose of this exchange is to minimize the costs and maximize the benefits. Rewards are defined as any resource to which a person can attach value such as support, comfort and affection. Costs in relationships are experiences that people want to avoid such as sacrifice, effort, energy and time invested. According to social exchange theory, people weigh the benefits and risks of social relationships. When the risks outweigh the rewards, people will abandon the relationship (Surma, 2015).

According to this theory, people weigh the potential benefits and risks of social relationships. People engage in the process of exchange to deal with the costs associated with exercising power. One of the important factors is reciprocity. The process begins when at least one person makes a move, and if the other person responds, new series of exchange initiate. Reciprocity is important for all exchanges because people assign meaning to exchanges, keep the record and change their interactions based on a reciprocity balance (Surma, 2015).

Online social networks are considered as a tool for information exchange. This exchange is based on graphical and written communication between users. Latest researchers suggested that social networkers including Facebook users seem to interact in accordance to social exchange theory. Social network users are able to minimize the cost of communication and maximize the strength of the relationship. For example: people can like the celebrity picture or video, where like is considered as a very low cost activity. Thus, people in online social networks behave like in real life situations. People use social networks to collect online friends and then talk to them about their lives without social norms limitations which may lead to the development of parasocial relationship (Surma, 2015).

\section{3- Goffman's Presentation of Self-theory}

Goffman suggests that when a person appears in the presence of others, he mobilize his activity to convey an impression to others. This impression to others lies in accordance with one own interest (Qi, Monod, Fang, \& Deng, 2018).

In addition, Goffman highlighted in his book the way in which people present themselves and their activities in their daily life, the way in which they control and guide the impression of people to them and the things he may or may not do to sustain his performance before them.

Furthermore, he suggested that the person should express himself in a way to give people the impression that will lead them to act in accordance with his own plan. This status is confirmed by the notion of control which implies that the person interest is to control the conduct of others (Qi, Monod, Fang, \& Deng. 2018).

In addition, Goffman theory is linked to strategic interaction which is based on game theory. There are many situations when a person can influence his own decision by knowing that other people are likely to find out his decision in advance. Strategic interaction is exchange of moves made on the basis of this kind of orientation to self and others (Goffman, 1979).

Goffman stated that technology facilitated the interaction between people especially with the invention of telephone, which was a way to interact socially. 
Researchers argued if Goffman's theory is still applicable to our currently online environment. Miller stated that electronic interaction is a natural extension to Goffman theory (Miller, 1995).

Latest researchers suggested that people use social network sites in order to present themselves as better than they actually are (Schwartz, \& Halegoua,2015). People online identity became more imaginative than their true one. This improvement of themselves on social networks is directly related to Goffman theory.

The personal brand is constructed across the social network sites that allow messages to be viewed publically and to spread through share and like. The short messaging style, coupled with easy categorization of a theme through a hashtag, allows the presentation of different interests in a visible way. Social networking sites are characterized by connections with others, regardless of whether the persons involved know each other. Thus, the online social networks provide their users the potential to present and perform different identities. In this case, the online identity can be considered as a part of the person wider identity.

According to Vaast, online identity facilitates persona adoption (Vaast, 2007). Waggoner argues that the term real world should be replaced by non-virtual world since the virtual identities of people that are created and maintained by users became as real to users as their non-virtual identities (Waggoner, 2009).

According to Ducheneaut, people prefer to engage with media figures who look better and stand out more than they do in real life. This form of identity exploration is one sided which may lead to parasocial relationship (Ducheneaut, 2009).

\section{4- Parasocial theory}

According to Horton and Wohl, parasocial interaction is considered as "simulacrum of conversational give and take between a person and a media figure which is created due to the private and personal style of the media figure" (Horton \& Wohl, 1956). The authors suggested that using a personal and direct conversation style by media figures can create a powerful intimacy with the audience (Perse,1990). Through repeated viewing, the audience would feel a bond of intimacy with media figures and develop loyalty toward them. Parasocial relationships resemble to face-toface and interpersonal relationships among people, but they are one sided since the media figure don't know the existence of the media viewer and don't have the obligation to maintain such a relationship (Borchers, 2002).

A character's persona is a part of the parasocial relationship. It is the fictional character of the person who develops a parasocial relationship with the media figure.

Horton and Wohl suggested that parasocial relationships start when the viewer thinks that media figure is in the circle of his peers (Horton \& Wohl, 1956). Repeated viewing of media figures, make audience think that they know media figures like they know their close friends including their personality, style, personal life, professional life and preferences.

This knowledge is accumulated and interpreted by the audience which makes them believe that they understand the media figure. Horton and Wohl emphasized on the notion of intimacy, which suggest that media character can create an influential relationship with the audience. Therefore, the audience wishes to receive advice from the media figure and do what the media figure says (Horton \& Wohl, 1956). Just as people rely on their family and friends for advices, information and approval for various decisions, audiences in a parasocial relationship with media figure often seek useful and important information from media figure (Ajzen, \& Fishbein, 1980). This indicated that media figures who have successfully established a strong parasocial relationship with audience can become brand endorsers (Boon \& Lomore, 2001).

\section{5- Reality television}

According to Nabi, Biely, Morgan, \& Stitt, reality television is defined as a "program that film celebrity as they live out events in their lives, artificial or real, as they occur (Nabi, Biely, Morgan, \& Stitt, 2003). It includes unplanned, unrehearsed interactions and actions among participants.

According to Dyer, viewers who relate themselves to the celebrity see themselves in that character. Thus, they create a quasi-friendship which in turn creates parasocial interaction that attaches them to the celebrity and its show (Dyer, 2010). 


\section{(C) Center for Promoting Education and Research (CPER) USA, www.cpernet.org}

In Lebanon, Reality TV shows had high rating among other TV genres since its first arrival. "The sister's" is the first reality TV show aired in 2015 on Lebanese Broadcasting Corporation International, LBCI. "The sisters" is a Lebanese version of the American reality TV series "Keeping up with the Kardashians" that portray the life of three sisters (Alice, Nadine and Farah Abdelaziz) who are very thin, tall, with big eyes and dark hair. The three sisters stated that they are huge fans of Kim, Khloe and Kourtney, who used their reality TV series to become famous (Newton, 2015). The three sisters are known for modeling and posting pictures of themselves on Instagram. They have thousands of followers on social media accounts (Alice: 584K followers, Farah: 506K followers, Nadine: 491K followers). They explained that their show has the same concept but different content than "Keeping up with the Kardashian" because Lebanon is an Arabic country and its culture is different than American culture (Newton, 2015). The idea of a Lebanese reality television show which concerns itself with three women generated diverse opinions in Lebanon (Newton, 2015).

\section{6- Perceived reality in television}

Many researchers conducted that the realistically perceived TV content has an effect on the attitudes and beliefs of audiences (Perse, 1986). According to Busselle and Greenberg, an individual who consider TV as more realistic is more likely to be influenced by that content (Buselle \& Greenberg, 2000). Papacharissi and Mendelson stated that the majority of reality TV viewers consider the behaviors, actions and interactions of celebrities are real (Papacharissi \& Mendelson, 2007).

Other researchers suggested that the perceived reality of the reality shows was the major reason for viewing (Ebersole \& Woods, 2007). The known format of reality TV show is a conversational style, or narrative with close surveillance on characters. In this setting, the content of the show must be made of honest, unrehearsed behaviors and reactions in front of the camera. Many camera techniques such as deep focus and close up, enhance reality and make people believe that they are watching real characters doing real life events (Ebersole \& Woods, 2007).

Perceived reality in television content has been related to influence parasocial relationship. According to Horton and Wohl, when celebrity seems real, the relationship between the audience and characters is easily created (Horton \& Wohl, 1956). They added that when a TV character acts in a vivid way, viewers feel that they are closer to them. Parasocial interaction is more likely to occur when celebrity adopt a conversational style by inviting response from audience members (Stefanone, Lackaff, \& Rosen, 2010). Thus, the perceived realism of celebrities is an important factor for forming a parasocial relationship.

The idea of engaging in conversation with a celebrity is exciting for audiences. When celebrities appear down to earth and realistic, people would feel that they are more approachable and, would be motivated to contact them directly (Leets, De Becker, \& Giles, 1995). The desire to know personal information about celebrities and the opportunity for friendship or face to face meetings were top motivations to contact celebrities. The majority of the viewers switched from sending fan mails to the usage of social networking sites to contact and communicate with celebrities (Leets, De Becker, \& Giles, 1995).

\section{7- Social media}

The first social media site was created in 1997 under the name of Six Degrees. It enabled users to upload a picture and make friends with other users. Social media sites began to explode in 2000 with the invention of Linkedin and Myspace. Youtube came out in 2005 which created a new way for people to share with other their videos. Facebook and Twitter both became available in 2006 and were considered as the most popular social networks on the internet. Other sites like Instagram began in 2010 which soon became a multi-billion dollars' platform used by 500 million people in a short period (Hendricks, 2013).

The most obvious reason for using social media is to create a sense of intimacy with their fans by disclosing their emotions and thoughts. The use of their opinion on controversial topics, the selfies, the spelling and grammatical errors in messages make social networks message from celebrity's intimate and personal. Thus, the barrier between celebrities and audiences is erased (Marwick \& Boyd, 2011).

Social media is effective in fostering parasocial relationship since audiences can engage in real conversations with their favorite celebrity. In addition, people can direct their messages to celebrities using Instagram and Facebook 
direct message, or using @ reply on Twitter. They can also write their comments on the celebrities wall (Marwick \& Boyd, 2011).

The communication via social networks tends to be ongoing and frequent. This constant communication enhances the feeling of bonding and intimacy, thus strengthening the parasocial relationship. Social networking sites are often confessional and self-disclosing. According to Horton and Wohl, celebrities who are privately and personally talking with people make them more response anticipated. Thus, creating parasocial relationships easily (Horton \& Wohl, 1956). This strategic managed self-disclosure can create digital intimacy and may actually make the audience interact with celebrities whom he cannot meet in person (Thompson, 2008). As long as the information about celebrity's increases and uncertainty about them decreases, people would feel that they understand the celebrity well. As a result, the parasocial relationship with celebrity will deepen (Thompson, 2008).

\section{CHAPTER 3}

\section{METHODOLOGY AND TECHNIQUE USED}

\section{1- Purpose}

The purpose of this thesis is to focus on the level of parasocial interactions in the online social media community. The relationship between consumer's time spent on social networking sites, as well as demographic factors (age and gender), will be gathered. The proposed research question is tested by estimating survey data from a sample of 50 members of social media.

\section{2- Method}

This study investigates the extent to which parasocial relationships are formed with the usage of social networking sites. A survey will be used to measure the perceptions and feelings toward their favorite celebrity. The survey which includes the gender and age of the participant will also determine how often the subjects use social networking sites and which sites they favor.

The population that will be studied will include participants from young adults 18 to 35 years' old who use social networking sites to follow celebrities. Young adults are appropriate subjects for this survey research because they are common users of social networking sites. To remain unbiased, a snowball sampling technique will be used. Snowball sampling is a non-probability sampling technique used when characteristics to be possessed by samples are difficult to find. This technique will be used because it is cost-effective and sampling can be completed in a short period (Dudovskiy, 2008). A link to the survey will be sent on the phone https://forms.gle/xhkELGVYX2z4L1Cm6

The mobile phone was chosen as an effective way to reach this large number of people who might respond as soon as possible. The survey will include an introduction explaining the purpose of the survey and asking for their agreement to be part of this research. Google Docs online survey software will be used to build and distribute the questionnaire. After the person agrees to participate in the survey, they will be asked to choose their age, gender, and their accounts on social networking sites. The questions will also include their usage of social networking sites as well as their celebrity perceptions. The survey will include multiple-choice questions.

\section{CHAPTER 4}

\section{RESULTS AND DISCUSSION}

In this section, I will analyze the results of the 50 people.

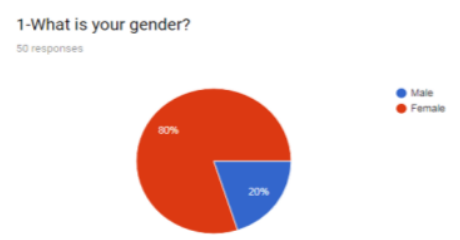

Fig 4.1 Gender of the participants 
This pie chart shows that $80 \%$ of respondents are women, while $20 \%$ of the respondents are men.

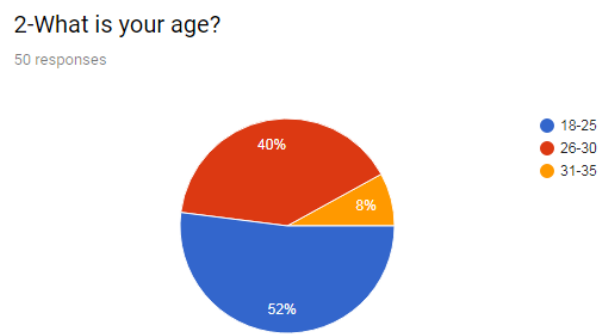

Fig 4.2 Age of the participants

This figure shows the age categories of respondents who participated in the questionnaire. $52 \%$ of the respondents are aged 18-25 years old, $40 \%$ are aged 26-30 years old, while only 8\% of the respondents are aged 31-35 years old.

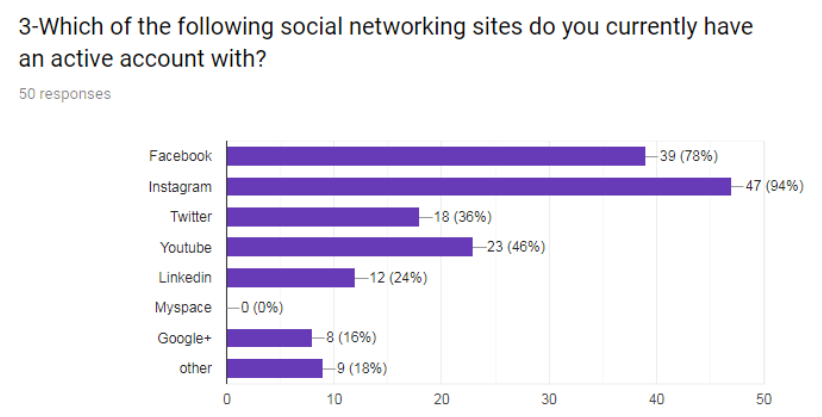

Fig 4.3 Social networking sites of the participants

This figure shows that of the total sample size, $94 \%$ of the respondents have an account on Instagram, $78 \%$ of the respondents have a Facebook account and 36\% have a twitter account. In addition, $46 \%$ of the respondents have a YouTube account, $24 \%$ have a LinkedIn account, and 18\% have other account while $16 \%$ have a Google+ account. None of the respondents had an account on My Space.

This shows that Instagram is the most social networking site used by participants.

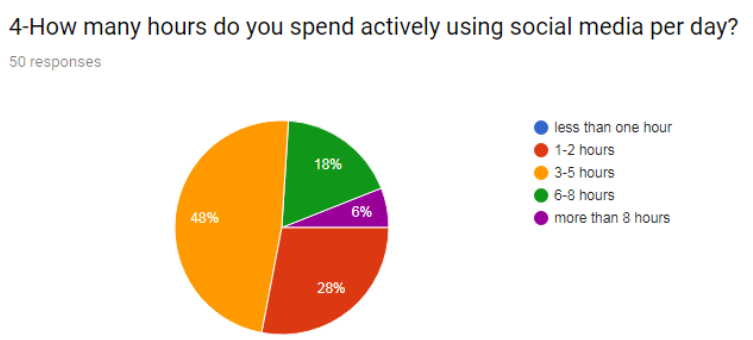

Fig 4.4 hours spent on social media

This figure shows that, out of 50 subjects who participated in this survey, nearly $48 \%$ of them spend 3-5 hours on social media per day. $28 \%$ of the subjects spend 1-2 hours per day, while $18 \%$ of them spend 6-8 hours per day. In addition, $8 \%$ of the respondents spend more than 8 hours on social media.

This shows that the majority of people spend 3-5 hours on social media per day. 


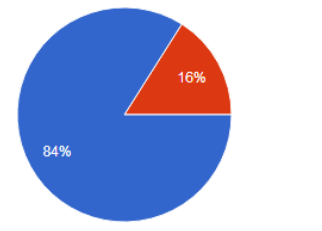

Fig 4.5 Celebrities follow

From this pie chart one realizes that that the majority of the participants $84 \%$ follow celebrities on social media, while only $16 \%$ don't follow celebrities on social media.
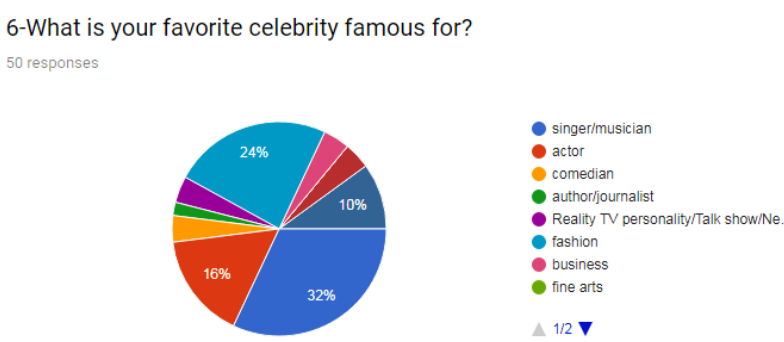

Fig 4.6 Celebrity categories

This figure shows that $32 \%$ of the total respondents follow singers/musicians on social media whereas $24 \%$ follow fashion people. In addition, $16 \%$ of respondents follow actor/actress, while $10 \%$ follow athlete on social media. The results also show that $4 \%$ of respondents follow chef, business people, comedian and reality TV personality. Only $2 \%$ follow author/journalist on social media.

This shows that singers/ musician are the most followed celebrity category by respondents.

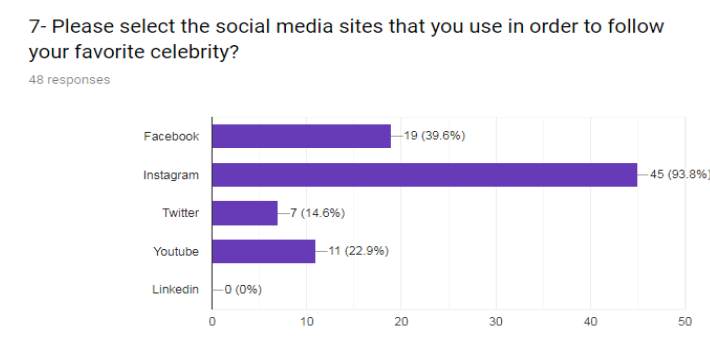

Fig 4.7 Social media sites of celebrities

We see from this chart that a high percentage of respondents $93.8 \%$ use Instagram to follow celebrities while $39.6 \%$ of the subjects use Facebook. In addition, $22.9 \%$ of subjects use YouTube and only $14.6 \%$ use Twitter to follow celebrities. None of the respondents use LinkedIn to follow celebrities.

\subsection{Primary research aim}

Our primary research aim is to find out the level of parasocial interaction among young Lebanese adults 
That is why we should identify:

\section{1-Whether or not they care about what happens to their favorite celebrity}

8-I care about what happens to my favorite celebrity.

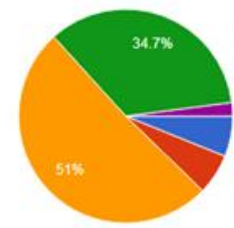

Fig 4.8 Caring about celebrity

Fig 4.8 shows that the majority of the respondents $(51 \%)$ stated that caring about their favorite celebrity is neutral. $34,7 \%$ of the respondents agree and $2 \%$ strongly agree with the statement, while $6 \%$ disagree and $6 \%$ strongly disagree.

\section{2-Whether or not they like to meet their favorite celebrity}

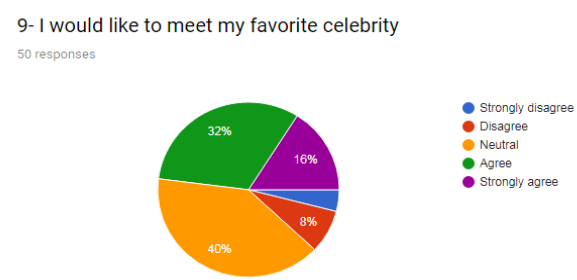

Fig 4.9 Meeting celebrity

The results show that $40 \%$ of respondents answered neutral. $32 \%$ of the respondents like to meet their favorite celebrity while $16 \%$ strongly agree. In contrast, $8 \%$ don't like to meet their favorite celebrity and $4 \%$ strongly disagree.

\section{3-Whether or not they can identify with their favorite celebrity}

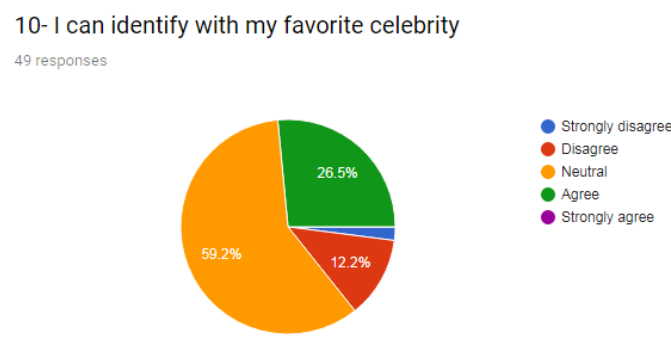

Fig 4.10 Identifying with celebrity

The majority of subjects, $59.2 \%$ replied to this statement as neutral. $26.5 \%$ agree that they can identify with their favorite celebrity. $12.2 \%$ disagree while only $2 \%$ strongly disagree. 


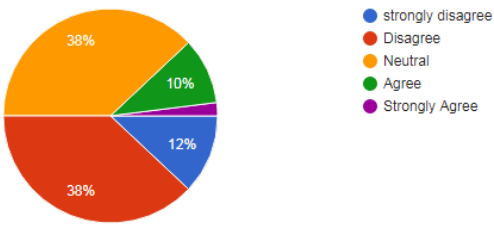

Fig 4.11 Imagining themselves as their favorite celebrity

The responses to this question as reflected in Fig. $4.1138 \%$ responded as neutral, while also 38\% disagree that they imagine themselves as their favorite celebrity. $10 \%$ agree that they imagine themselves as their favorite celebrity, while $2 \%$ strongly agree.

Whether or not they like to be more like their favorite celebrity

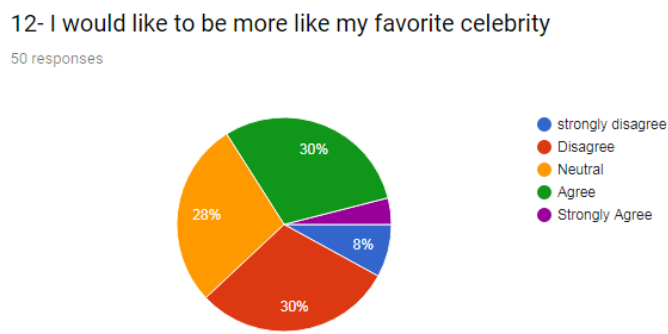

Fig 4.12 Being like celebrity

As can be seen from Fig, 4.12, 30\% agree that they like to be more like their favorite celebrity, while $4 \%$ strongly agree. In contrast, $30 \%$ disagree and $8 \%$ strongly disagree. $28 \%$ responded to this question as neutral. Whether or not they usually agree with their favorite celebrity

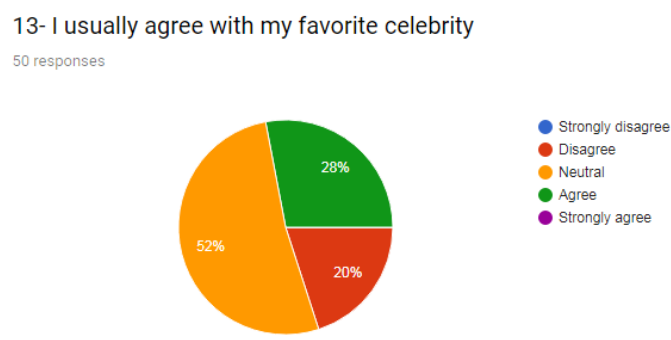

Fig 4.13 Agreeing with favorite celebrity

The figure 4.13 shows that $28 \%$ usually agree with their favorite celebrity while $20 \%$ disagree. $52 \%$ of the participants responded as neutral.

Whether or not they can trust their favorite celebrity 


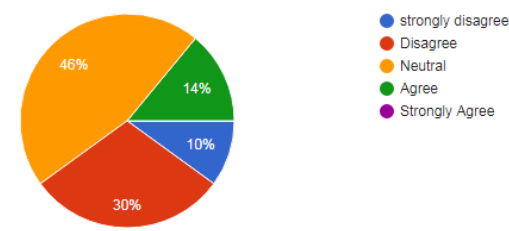

Fig 4.14 Trusting their favorite celebrity

$46 \%$ of the participants responded as neutral, while $30 \%$ disagree and $10 \%$ strongly disagree. Only $14 \%$ of the respondents feel like they can trust their favorite celebrity.

Whether or not they are loyal to their favorite celebrity

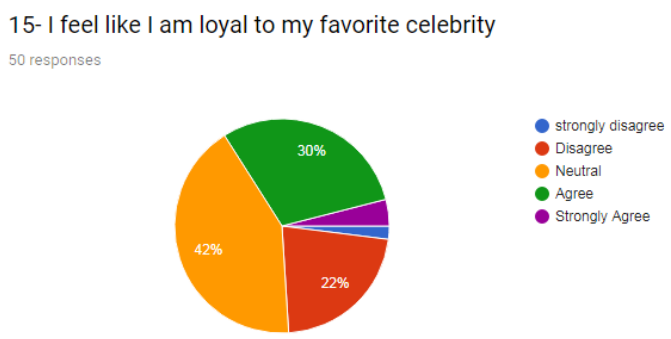

Fig 4.15 Feeling loyal to the favorite celebrity

As can be seen from figure $4.15,42 \%$ of the participants responded as neutral. $30 \%$ feel like they are loyal to their favorite celebrity and $4 \%$ strongly agree. In contrast, $22 \%$ of the participants disagree and $2 \%$ strongly disagree. Whether or not they enjoy interacting with others who follow their favorite celebrity

16-I would enjoy interacting with others who follow my favorite celebrity

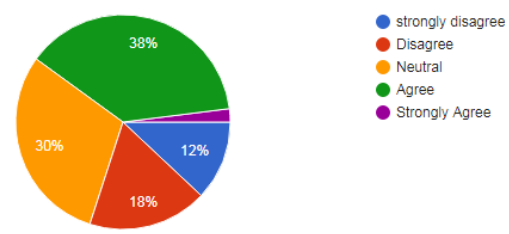

Fig 4.16 Interacting with others who follow favorite celebrity

As shown in Fig 4.16, 38\% of the participants agree that they enjoy interacting with others who follow my favorite celebrity and $2 \%$ strongly agree. $30 \%$ of the participants responded as neutral. $18 \%$ of the respondents disagree with this statement and $12 \%$ of the respondents strongly disagree.

How often they check their favorite celebrity updates 


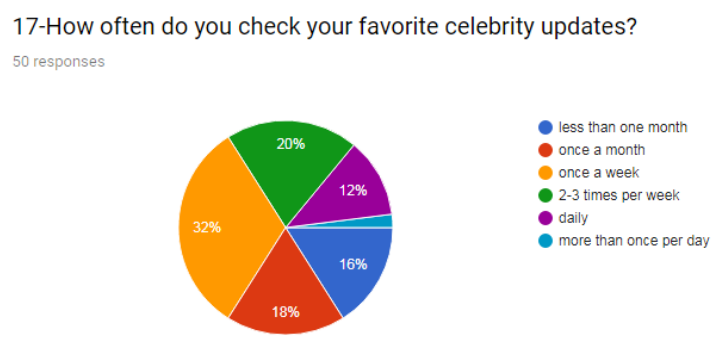

Fig 4.17 Checking the favorite celebrity updates

As shown in fig 4.17, 32\% stated that they check their favorite celebrity updates once a week. $20 \%$ of them check 2-3 times per week and $18 \%$ check once per month. $16 \%$ of the participants check their favorite celebrity updates less than one month and $12 \%$ check them daily. Only $2 \%$ check them more than once per day.

How many times they tried to interact with their favorite celebrity on social media

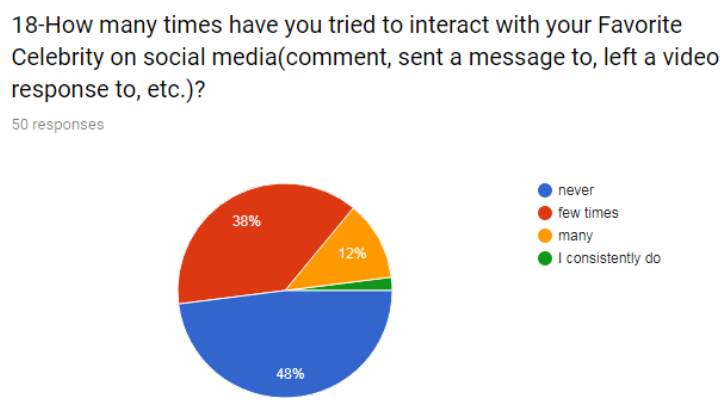

Fig 4.18 Interacting with favorite celebrity

From this figure 4.18 , one realizes that $48 \%$ of the respondents never tried to interact with their favorite celebrity. $38 \%$ of the respondents tried a few times, and $12 \%$ of the respondents tried many times. Only $2 \%$ of the respondents consistently try to interact with their favorite celebrity.

These findings indicate that the level of parasocial interaction among Lebanese young adults is neutral. When asked about the level of parasocial interaction, the majority of the respondents answered with neutral, but the percentage of the agreement to these statements is also high. We can conclude that the level of parasocial interaction is neutral, but it is present in Lebanese society.

\section{Chapter 5}

\section{CONCLUSION}

\subsection{Summary of the Findings}

The aim of this research was to discover the level of parasocial interaction among Lebanese young adults. As can be seen, the self-administered questionnaire resulted in 50 respondents, 80 of whom were female and 20 of whom were male. The results showed that the level of parasocial interaction among Lebanese young adults is neutral. This confirms with social penetration theory which suggests that celebrities share information with their fans and followers which might help in developing parasocial interaction. The participants agreed with $34.7 \%$ that they care about celebrity's life, while $51 \%$ neutrally responded to this question. In addition, the results contradict social exchange theory which proposes that people use social media to collect online friends and then talk to them about their lives without social limitations. $48 \%$ of the participants stated that they never tried to interact with their favorite 
celebrity. Furthermore, the results confirm with Goffman's theory which proposes that people prefer to engage with celebrities who look better and stand out more than they do in real life. $26.5 \%$ of the participants stated that they like to identify themselves with the celebrity, while $59.2 \%$ responded with neutral.

\subsection{Limitations of the study}

First of all, the study will be conducted in Lebanon, therefore the generalization of findings from this study will be limited to the Lebanese population. Future studies may be conducted in other countries for validation of the findings of the present study.

Second, the sample included only 50 people. Future studies may be conducted to include a larger sample.

\section{Acknowledgments}

I would like to thank my husband and my family for their continuous support.

\section{REFERENCES}

Ajzen, I. \& Fishbein, M. (1980). Understanding Attitudes and Predicting Social Behavior. Englewood Cliffs, NJ: Prentice-Hall.

Allaby, M. (n.d). Para-social interaction. Oxford reference. Retrieved from http://www.oxfordreference.com/view/10.1093/oi/authority.20110803100305809

Bennett, N., Rossmeisl, A., Turner, K., Holcombe, B., Young, R., Brown, T., \& Key, K. (2017, March 23). Parasocial Relationships: The Nature of Celebrity Fascinations. Retrieved from https://www.findapsychologist.org/parasocial-relationships-the-nature-of-celebrity-fascinations/

Boon, S. \& Lomore, C. (2001). Admirer celebrity relationships among young adults. Human Communication Research, Vol.27, pp.432-465.

Borchers, T. (2002). Persuasion in the Media Age. Boston: McGraw Hill.

Bullingham, L., \& Vasconcelos, A. (2013). The presentation of self in the online world: Goffman and the study of online identities. Journal of information science. Vol.39, pp. 101-112.

Busselle, R., \& Greenberg, B.(2000). The nature of television realism judgments: A reevaluation of their conceptualization and measurement. Mass Communication \& Society, Vol. 3, pp. 249-268.

Carpenter, A., \& Greene,K. (2016). Social penetration theory. Rutgers University, USA. Retrieved from file:///C:/Users/melisa/Desktop/ACGreene-SPT.pdf

Chung, S., \& Cho, H. (2017, November 14). Parasocial relationship via reality TV and social media: its implications for celebrity endorsement. Retrieved from

https://www.researchgate.net/publication/314399228_Fostering_Parasocial_Relationships_with_Celebrities_on_Soci al_Media_Implications_for_Celebrity_Endorsement_CELEBRITY_PARASOCIAL_RELATIONSHIPS_ON_SO CIAL_MEDIA?_sg=5USzrupB0UYUEcTERIWBD21HvTTMPwtXs2yJ7tDSUy3pY2gDCC_eeaV3Yk151RP7SSmwT9XjA

Cialdini, R. B., Borden, R. J., Thorne, A., Walker, M., Freeman, S., \& Sloan, L. R. (1976). Basking in reflected glory: Three (football) field studies. Journal of Personality and Social Psychology, Vol. 34(3), pp. 366-375.

Clark, J. (2018, July 08). 30 Crazy Social Media Facts That Might Change How You Think About Marketing. Retrieved from https://www.searchenginejournal.com/social-media-facts/258533/

Cunningham, C. (2013). Social networking and impression management: self-presentation in the digital age. Lanham: Rowman and Littlefield Publishing Group, Inc.

Ducheneaut N. (2009). Body and mind: a study of avatar personalization in three virtual worlds. In: Proceedings of the 27th international conference on Human factors in computing systems (CHI '09). New York: ACM Press, pp. $1151-1160$. 
Dudovskiy, J. (2008). Snowball sampling. Retrieved from https://research-methodology.net/sampling-in-primarydata-collection/snowball-sampling/

Dyer, C. (2010). Reality Television: using para-social relationship theory and economic theory to define the success of network reality programming. University of North Texas. Retrieved from https://digital.library.unt.edu/ark:/67531/metadc33144/m2/1/high_res_d/thesis.pdf

Ebersole, S., \& Woods, R. (2007). Motivations for viewing reality television: A uses and gratifications analysis. Southwestern Mass Communication Journal, Vol. 23, pp. 23-42.

End, C. (2001). An examination of NFL fans' computer mediated BIRGing. Journal of Sport Behavior, Vol. 24(2), pp. 162-181.

Giles, D. (2002). Parasocial interaction: A review of the literature and a model for future research. Media psychology, Vol. 4, pp. 279-305.

Goffman, E. (1979). The presentation of self in everyday life. New York: Bantam Doubleday Dell publishing group, Inc.

Hendricks, D. (2013, May 08). Complete History of Social Media: Then and Now. Small business trends. Retrieved from https://smallbiztrends.com/2013/05/the-complete-history-of-social-media-infographic.html

Horton, D., \& Wohl, R. (1956, November 08). Mass Communication and Para-Social Interaction. pp.215-229. Retrieved from https://www.tandfonline.com/doi/abs/10.1080/00332747.1956.11023049

Laken,A. (2009). Parasocial relationships with celebrities: An illusion of intimacy with mediated friends. University of Nevada, Las Vegas. Retrieved from

file://C:/Users/melisa/Desktop/Parasocial\%20relationships\%20with\%20celebrities_\%20An\%20illusion\%20of\%20in timac.pdf

Leets, L., De Becker, G., \& Giles, H. (1995). Fans: Exploring expressed motivations for contacting celebrities. Journal of Language and Social Psychology, Vol. 14, 1-2, pp.102-123

Marwick, A., \& Boyd, D. (2011). To see and be seen: Celebrity practice on Twitter. Convergence: The International Journal of Research into New Media Technologies, Vol.17, pp.139-158.

Marwick, A., \& Boyd, D. (2011). To see and be seen: Celebrity practice on Twitter. Convergence: The International Journal of Research into New Media Technologies, Vol. 17(2), pp.139-158.

McCutcheon, L., Lange, R., \& Houran, J. (2010). Conceptualization and measurement of celebrity worship. British Journal of Psychology, Vol. 93(1), pp. 67-87.

Miller, H. (1995). 'The presentation of self in electronic life: Goffman on the Internet', Proceedings of the embodied knowledge and virtual space conference, London, UK. Retrieved from http://www.dourish.com/classes/ics234cw04/miller2.pdf

Nabi, R., Biely, E., Morgan, S., \& Stitt, C. (2003). Reality-based television programming and the psychology of its appeal. Media Psychology, Vol. 5, pp.303-330.

Newton, J. (February, 2015). Three gorgeous, pouting, selfie-loving sisters. No, it's not Kim, Khloe and Kourtney... it's Lebanon's answer to the Kardashians who will star in new TV show. Retrieved from http://www.dailymail.co.uk/news/article-2952595/Lebanon-s-answer-Kardashians-Abdel-Aziz-sisters-star-newTV-show.html

Papacharissi, Z., \& Mendelson, A. (2007). An exploratory study of reality appeal: Uses and gratifications of reality TV shows. Journal of Broadcasting \& Electronic Media, Vol. 51, pp. 355-370

Perse, E. (1986). Soap opera viewing patterns of college students and cultivation. Journal of Broadcasting \& Electronic Media, Vol. 30, pp. 175-193.

Perse, E. (1990). Involvement with local television news cognitive and emotional dimensions. Human Communication Research, Vol. 16, pp.556-581 
Phelps, C. (2011, November 08). Parasocial Relationships and Social Media Usage. The Rochester Institute of Technology. Retrieved from

http://www.google.com/url?sa=t\&rct=j\&q=\&esrc=s\&source=web\&cd=6\&ved=0ahUKEwjc2MLs5LzcAhVHy6QKH ZzNA9AQFghJMAU\&url=http\%3A\%2F\%2Fscholarworks.rit.edu\%2Fcgi\%2Fviewcontent.cgi\%3Farticle\%3D40 92\%26context\%3Dtheses\&usg=AOvVaw2QdAj_rZl5wxN1NK6VFrev

Qi, J., Monod, E., Fang, B., \& Deng, S. (2018). Theories of social media: Philosophical foundations. pp.1-9. Retrieved from https://reader.elsevier.com/reader/sd/79F3B1BAF175F41AA3A89DB42A8E62BCAA27DA1BB0A3CCE8F28C CA4003C41C666A6CBF885EFECB57C79EF21EFA274A55

Rindova, V., Pollock, T., \& Hayward, M. (2006). Celebrity firms: The social construction of market popularity. Academy of Management Review, Vol. 31(1), pp. 50-71.

Schwartz, R., \& Halegoua, G. (2015). The spatial self: location based identity performance on social media. New media soc. Vol. 17 (10):1643-60

Spitzberg, B., \& Cupach, W. (2007). Fanning the flame of fandom: celebrity worship, parasocial interaction, and stalking. Conference Paper - International Communication Association, pp. 1-35

Stefanone, M., Lackaff, D., \& Rosen, D. (2010). The relationship between traditional mass media and "social media": Reality television as a model for social network site behavior. Journal of Broadcasting \& Electronic Media. Vol. 54, 3, pp.508-525.

Stever, G. (2017). Parasocial Theory in Communication. Oxford bibliographies. Retrieved from http://www.oxfordbibliographies.com/view/document/obo-9780199756841/obo-9780199756841-0181.xml

Surma, J. (2015, July 17). Social exchange in online social networks. The reciprocity phenomenon on Facebook. Institute of Informatics and Digital Economy, Warsaw School of Economics, Aleja Niepodleglosci 162, 02-554 Warsaw, Poland.

Taylor, A., \& Altman, I. (1987). Communication in interpersonal relationships: Social penetration processes. In M. E. Roloff \& G. R. Miller (Eds.), Interpersonal processes: New directions in communication research, pp. 257-277. Thousand Oaks, CA: Sage.

Thompson, C. (2008). Brave new world of digital intimacy. The New York Times. Retrieved from http://www.nytimes.com/2008/09/07/magazine/07awareness-t.html?pagewanted=all\&_r=0

Vaast, E. (2007). Playing with Masks: fragmentation and continuity in the presentation of self in an occupational online forum. Information Technology \& People; Vol: 20, pp. 334-351.

Waggoner, Z. (2009). My avatar, myself: identity in video role-playing games. London: McFarland \& Company, p. 1. 